\title{
Chapter
}

\section{TREATMENT REVIEW OF HOSPITAL ACQUIRED INFECTIONS}

Janay Bailey, ${ }^{\mathbf{1}}$ George Udeani, ${ }^{2}$ and Salim Surani2 ${ }^{*}$

${ }^{1}$ Bay Area Medical Center, Corpus Christi, Texas, 78412, USA

${ }^{2}$ Texas A\&M University, College Station, Corpus Christi, Texas, 78412, USA 


\section{Contents}

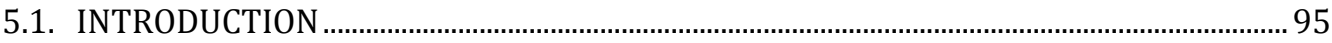

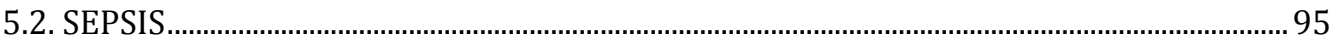

5.3. HOSPITAL ACQUIRED PNEUMONIA/ VENTILATOR ASSOCIATED PNEUMONIA........ 97

5.4. CATHETER-ASSOCIATED URINARY TRACT INFECTION ...................................................... 98

5.5. CENTRAL LINE-ASSOCIATED BLOOD STREAM INFECTION ...........................................102

5.6. HOSPITAL ONSET CLOSTRIDIUM DIFFICILE …...............................................................104

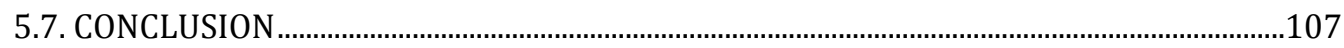

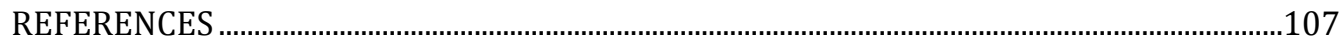




\subsection{INTRODUCTION}

Hospital acquired, or nosocomial, infections are monitored closely by agencies such as the Center for Disease Control and Prevention (CDC) and the U.S. Department of Health and Human Services (HHS) for prevention, control, and improvement of patient safety [1,2]. These infections are associated with approximately two million illnesses, leading to over 95,000 deaths and significant costs of about $\$ 33$ billion every year [3]. Critically ill patients are at a higher risk for serious infections caused by multi-drug resistant organisms (MDROs). Particularly in the intensive care unit (ICU), nosocomial infections lead to increased length of stay, greater morbidity and mortality rates, and need for post-hospitalization care [4]. Many factors contribute to the higher risks in the ICU including invasive devices, surgical or traumatic wounds, disruption of skin barriers and mucosa, and alterations in adaptive immune responses [4]. Other risk factors include immunosuppression, longer hospital stay, multiple chronic conditions, recent invasive procedures, previous antibiotic use within 90 days, and even receiving care in the critical care units [1]. All hospitals should have an antibiogram readily available so that appropriate empiric therapy can be implemented and to trend patterns of resistance [5,6]. Antimicrobial stewardship is essential in reducing the vastly spreading resistance patterns [7,8]. This chapter will focus on common conditions that occur in critically ill patients, common causative organisms in this population, and evidence-based treatment.

\subsection{SEPSIS}

Sepsis is preventable yet occurs in more than 1.5 million people in the United States per year, leading to high mortality rates of approximately 250,000 deaths a year $[7,9]$. Previously known as the presence of infection along with systemic manifestations of an infection, the definition of sepsis has been updated in order for a clear and consistent concept to be understood [10]. Sepsis- 1 was often misdiagnosed and improperly treated. According to a study, patients diagnosed with sepsis-1 that were not included in the diagnosis of sepsis-3 had fewer 21-day mortality rates than those diagnosed with sepsis-3 (6.96\% 21-day mortality rate for those meeting sepsis-1 criteria) [11]. In addition, patients diagnosed with sepsis under the sepsis-3 criteria who did not meet the sepsis-1 criteria had a higher mortality rate $(10.76 \% 21$-day mortality rate for those meeting sepsis-3 but not sepsis-1 criteria) [11].

In the newer 2016 definition, or sepsis-3, sepsis is defined as "life-threatening organ dysfunction caused by a dysregulated host response to infection" 
$[12,13]$. Sequential [Sepsis-related] Organ Failure Assessment (SOFA) Score is based on respiration, coagulation, liver, cardiovascular system, central nervous system, and renal function. The risk of mortality increases with higher scores. A quick SOFA (qSOFA) score may be used to promptly identify patients at a greater risk for longer ICU stay or mortality which includes: (1) altered mental status (AMS), (2) systolic blood pressure (SBP) $\leq 100 \mathrm{~mm} \mathrm{Hg}$, or (3) respiratory rate $\geq 22$ breaths/min [13]. Severe sepsis is no longer considered, and septic shock is defined as "a subset of sepsis in which underlying circulatory and cellular metabolism abnormalities are profound enough to substantially increase mortality." Patients with septic shock may have the qSOFA characteristics as well as serum lactate $>2 \mathrm{mmol} \mathrm{L}^{-1}$ and hypotension that requires vasopressors to maintain a mean arterial pressure (MAP) of $\geq 65 \mathrm{~mm} \mathrm{Hg}$ [13]. In Sepsis 1, Systemic Inflammatory Response Syndrome (SIRS) criteria are ambiguous and do not accurately reflect a dysregulated response due to infection when two or more conditions are met. SIRS consist of temperature $>38^{\circ} \mathrm{C}$ or $<36^{\circ} \mathrm{C}$, heart rate (HR) $>90$ beats/min, respiratory rate (RR) $>20$ breaths/min (or $\mathrm{PaCO}_{2}<32 \mathrm{~mm} \mathrm{Hg}$ ), and white blood cell (WBC) $>12,000$ cells $/ \mathrm{mm}^{3}$ or $<4,000$ cells $/ \mathrm{mm}^{3}$ [13].

As with any other medical emergency, time is an essence and therapy should be initiated as soon as possible to decrease mortality and morbidity. The Surviving Sepsis Campaign of 2016 [14] recommends that in the presence of hypoperfusion, fluid resuscitation with a crystalloid be given at a volume of $30 \mathrm{~mL} \mathrm{~kg}^{-1}$ within the first $3 \mathrm{~h}$, though controversial. It is imperative to modify the volume of fluid resuscitation in identified patients [15]. Some patients may require more, or less, fluid and should be clinically evaluated based on heart rate, blood pressure, oxygen saturation, urine output, capillary refill, appearance of skin mottling, etc. $[14,15]$. Crystalloid fluid may be given in $500 \mathrm{~mL}$ challenges adding up to an initial resuscitation of $20-30 \mathrm{~mL} \mathrm{~kg}^{-1}$, measuring responsiveness by an increase in stroke volume [15,16]. Some authors suggest evaluating the inferior vena cava with an ultrasound to assess fluid benefit to help avoid over-resuscitation [15,17]. Lactate may be used as a guide in determining adequate tissue perfusion, though it is not a direct measurement of this marker $[14,18]$. An important factor in sepsis, as well as antimicrobial stewardship, is to collect appropriate cultures prior to initiation of antimicrobial therapy to prevent sterilization [14]. De-escalating therapy is essential in decreasing resistance, side effects, and costs. In cases where timely collection of specimens is not feasible, it may be more beneficial to administer therapy than to prolong treatment. At least two sets of 20-30 mL of blood per culture, aerobic and anaerobic, should be obtained subsequently within a short interval time due to extreme urgency $[14,19]$. Once sepsis or septic shock is determined, intravenous (IV) administration of empiric antibiotics is recommended within one hour [14]. Evidence has shown that mortality increases with each additional hour as well as in failure to initiate appropriate empiric therapy to cover all likely pathogens [20-23]. Procalcitonin (PCT) 
levels may be used to consider stopping empiric treatment or determining duration. Data has shown the use of PCT helps to reduce treatment duration and aid in early de-escalation for bacterial infections [24-26], however, a metaanalysis did not produce the same evidence of PCT benefit [27]. The vasopressor of choice, when needed, is norepinephrine due to inotropic and vasoconstrictive effects. Norepinephrine is able to increase the MAP with small changes in heart rate and has less tachycardic effects than dopamine.

\subsection{HOSPITAL ACQUIRED PNEUMONIA/ VENTILATOR ASSOCIATED PNEUMONIA}

Hospital acquired pneumonia (HAP) presents as a new lung infiltrate appearing $48 \mathrm{~h}$ or longer after being hospitalized, along with clinical signs and symptoms [28]. Clinical presentation includes an onset of a fever, purulent sputum, leukocytosis, and a decline in oxygen levels. Ventilator associated pneumonia (VAP) will appear the same way, however, it occurs $48 \mathrm{~h}$ after endotracheal intubation [28]. The Infectious Disease Society of America (IDSA) guidelines for HAP/VAP recognize that there is no gold standard for diagnosis but suggests using non-invasive methods with semiquantitative cultures instead of invasive methods. They do recognize, however, that this is a "weak recommendation" with "low-quality evidence" [28]. The risk factor for Multi Drug Resistance Organisms (MDROs) in HAP consists of the use of intravenous antibiotic therapy in the previous 90 days. The following conditions are risk factors concerning MDROs in VAP: intravenous antibiotic use in the previous 90 days [29-31], hospitalization for 5 days or longer before the onset of VAP [30,32-34], septic shock during VAP [31], acute respiratory distress syndrome (ARDS) [29,31] and renal replacement therapy prior to VAP [29]. It is recommended that patients with HAP/VAP receive empiric coverage for Staphylococcus aureus. Methicillin resistant Staphylococcus aureus (MRSA) may be empirically treated in HAP if $>20 \%$ of the local unit isolates are MRSA, or if the local isolates are between 10-20\% for VAP, risk factors for resistance are present, or the patient has a high risk of mortality [28]. Vancomycin and linezolid are the drugs of choice for MRSA pneumonia. Other agents that have also been studied for MRSA include ceftaroline, teicoplanin, telavancin, tedizolid, and tigecycline [35-37]. Patients with HAP/VAP should also receive empiric therapy for Pseudomonas aeruginosa, and other gram-negative bacilli [28]. Empiric coverage for methicillin-sensitive Staphylococcus aureus (MSSA) may include piperacillin-tazobactam, cefepime, levofloxacin, imipenem, or meropenem [28]. Coverage for MSSA when confirmed can include oxacillin, nafcillin, or cefazolin [28]. Treatment of gram negative organisms are a major concern due to their patterns of becoming resistant to almost all considered antibiotics. Common gram-negative pathogens of pneumonia include 
Pesudomonas aeruginosa, Escherichia coli, Klebsiella pneumonia, and Acinetobacter species [38]. For this reason, when $>10 \%$ of local gram-negative isolates are resistant to a single agent or the resistant patterns are unknown, or a risk for infections by an MDRO is present, the guidelines suggest double pseudomonal coverage with two antibiotics from different classes [28]. Single gram-negative therapy with an aminoglycoside is not recommended. Two antipseudomonal agents should also be used when structural lung disease is present such as cystic fibrosis or bronchiectasis [39].

Pan-resistant or nearly pan-resistant patterns with Pseudomonas and Acinetobacter are increasing at an alarming rate. Approximately $13 \%$ of healthcare-associated Pseudomonas is multidrug resistant, where at least three antibiotic classes are no longer effective, causing more than 6,000 infections a year. At least $63 \%$ of Acinetobacter strains are multidrug-resistant and may cause pneumonia in critically ill patients [40]. Preventative strategies play an integral role in slowing or preventing drug resistance and spread. Appropriate initial antibiotics, timing of initiation, and drug concentration are heavily involved in successful treatment and reduction of in-hospital mortality [38]. Standard precautions include hand washing with soap and water or alcoholbased disinfectants prior to entering and upon exiting patients' rooms, [1] local surveillance of hospital acquired infections with infection control programs, and intervention protocols [41]. Specific methods to prevent VAP include [42]:

- avoiding intubation if possible

- limiting sedation and assessing the sedation need

- early mobility

- minimize pooling of tracheal secretions above the endotracheal tube cuff

- elevate the head of the bed $30^{\circ}-45^{\circ}$

- maintain ventilator circuits

These practices aid in preventing the cause or worsening of VAP and help to decrease ventilator days, hospital length of stay, costs, and mortality.

\subsection{CATHETER-ASSOCIATED URINARY TRACT INFECTION}

Catheter-associated urinary tract infections (CAUTIs) are defined as the presence of a urinary tract infection (UTI) signs or symptoms in a patient with an indwelling urethral, indwelling suprapubic, or intermittent catheter with 1000 colony forming units ( $\mathrm{cfu}) / \mathrm{mL}$ and one or more isolated bacterial species excreted from a single catheter urine specimen or a midstream voided urine from a patient whose urethral, suprapubic, or condom catheter was removed 
within $48 \mathrm{~h}$. UTI symptoms cannot be identified by another source and typically warrants antimicrobial therapy [43]. Signs and symptoms of a CAUTI include fever, rigors, altered mental status (AMS), malaise, lethargy, flank pain, costovertebral angle tenderness, acute hematuria, and pelvic discomfort. This also includes patients whose catheters have been removed within $48 \mathrm{~h}$ but still experience dysuria, urgent or frequent urination, or suprapubic pain or tenderness. Spinal cord injury patients with CAUTIs may experience symptoms mentioned above as well as increased spasticity, onset of urinary incontinence, autonomic dysreflexia, autonomic hyperreflexia, and sense of unease or discomfort during urination $[44,45]$.

On average, $15-25 \%$ of hospitalized patients receive urinary catheters, and approximately $75 \%$ of UTIs are caused by catheters [46]. Indwelling urinary catheters are an independent risk factor for UTIs. The risk of developing CAUTIs is higher with prolonged use of urinary catheters, therefore, it is important to remove them as soon as they are no longer indicated. In the United States, CAUTIs cause up to $40 \%$ of all hospital-acquired infections (HAIs) with a risk of developing catheter-associated (CA) bacteriuria increasing by $3-8 \%$ per in situ catheter day $[2,44,47,48]$. Bacteriurias are the most common causes of gram-negative bacteremias in hospitalized patients and attribute to approximately $15 \%$ of nosocomial bacteremias $[44,49]$.

Urinary catheters should only be used when indicated. Incontinence should not be managed with a urinary catheter unless the patient has failed all other methods and is considering using this alternative. Every institutional facility should develop a policy or protocol with acceptable indications for urinary catheters and educate their staff. An order from the provider should be required before a catheter is placed. Catheters are indicated in the following conditions:

- urinary retention that has failed medical management and surgery is not indicated. This includes temporary or long-term drainage $[44,50]$.

- Urinary incontinence where behavioral and pharmacological management or other less invasive interventions, such as incontinence pads or external collecting devices, are not effective or appropriate. Catheters can also be used in terminally ill patients with urine incontinence for comfort measures [44,50].

- When exact urine output observations are needed $[44,50]$.

- If a patient is unwilling or physically unable to collect urine such as during extended surgical procedures or a genitourinary procedure $[44,50]$.

Urinary catheters should be removed as soon as they are no longer indicated to help reduce CA-bacteriuria and antimicrobial use. Institutions should also implement alert systems with possible automatic stop-orders to decrease unnecessary catheterization. While it is imperative to practice preventative 
strategies in efforts to avoid causing a CAUTI, it is impossible to avoid them especially in patients who need long-term catheterization [44].

Mostly all patients with an indwelling catheter will be bacteriuric by 30 days. Short term catheterization is $<30$ days while long term is $>30$ days. The longer a patient is catheterized, the more likely they are to experience complications such as bacteriuria, bacteremia, catheter obstruction, stone formation, infections, fistula, incontinence, and bladder cancer [51]. Other factors that contribute to the development of CA-bacteriuria are the female sex, older age, diabetes mellitus, no usage of antimicrobials, bacterial growth in the drainage bag or urethral meatus cultures, non-sterile catheter insertion, lack of perineal care, increased serum concentration when catheter is inserted, and deadly underlying diseases [52-54].

Catheter-associated asymptomatic bacteriuria (CA-ASB) is defined as bacteria being present in the urine while having no urinary tract signs or symptoms and typically does not require treatment [43]. Infectious Diseases Society of America (IDSA) adds that this includes patients with 100,000 colony forming units (cfu)/mL and one or more urine bacterial species and have an indwelling urethral, indwelling suprapubic, intermittent catheterization, or a man with a newly placed condom catheter in a single catheter urine specimen. These patients should not be screened or treated unless they are pregnant women or being evaluated for research [44].

The term CA-bacteriuria does not have a true definition. It is often used when a clear differentiation between CAUTI and CA-ASB is not made, which most of the time is CA-ASB. Antimicrobials are often inappropriately used in these patients and contribute to the growing number of resistant organisms [44]. In a freshly placed catheter, colony counts of $100 \mathrm{cfu} \mathrm{mL}^{-1}$ can be considered bacteriuria because this is highly representative of true bladder bacteriuria compared to a voided specimen. Lower colony counts are acceptable in catheter urine samples since they are not as frequently contaminated by periurethral flora like voided urine cultures. If symptoms persist during CAbacteriuria that is non-contributable to another condition, it may be reasonable to treat the patient and monitor symptoms [44].

Pyuria, the presence of white blood cells in the urine, is not diagnostic of CAbacteriuria or CAUTI and should not be used to distinguish the two or initiate antimicrobial therapy. However, if pyuria is not present in a symptomatic patient, diagnoses other than CAUTIs should be considered. In addition, malodor or cloudy urine cultures alone should not be used to acquire a urine sample, initiate antimicrobial therapy, or characterize CAUTI from CA-ASB [44].

Naturally when a catheter is inserted, host defense mechanisms are disrupted and easier access for inoculation to the surface permits colonization with uropathogens $[43,44]$. Significant residual urine in the bladder below the catheter promotes true infection [43,55]. Replicating bacteria can form 
biofilms that eventually become polymicrobic and lead to antimicrobial resistance, especially in long-term catheters. Biofilms can form catheter encrustations that may obstruct catheter urine flow. Encrustations are usually produced by Proteus species, Morganella morganii, Pseudomonas aeruginosa, Klebsiella pneumoniae, and Providencia stuartii. These organisms can hydrolyze urine urea to free ammonia, causing an increase in $\mathrm{pH}$ aiding in the precipitation of minerals [54].

CAUTIs are frequently polymicrobial and caused by multidrug-resistant (MDR) uropathogens. Patients with short-term catheters who develop bacteriuria are normally affected by a single pathogen [56]. Escherichia coli is the most common organism isolated, although other major species such as Klebsiella, Serratia, Citrobacter, Enterobacter, Candida, Enterococci, and P. aeruginosa, are also isolated [57,58].

The majority of catheters are made from latex, however, use of silicone-based catheters is increasing due to the number of patients with latex allergies and the incidence of inflammation, toxicity, urethritis, and encrustations with latexbased catheters $[59,60]$.

The concentration of organisms increase the longer an indwelling catheter is in place and decrease significantly when a new catheter is inserted [61]. In shortterm catheterization, it is recommended for cultures to be obtained by retrieving a sample from the catheter port using aseptic technique or by piercing the tubing with a needle and syringe if a port is not being used [57]. For long-term indwelling catheters, it is preferred that cultures be obtained from a freshly replaced catheter. This should be done prior to administration of antimicrobial therapy in symptomatic patients [62]. Specimen should not be collected from the drainage bag.

Routine prophylactic treatment for CAUTIs is not recommended due to increased risk of antimicrobial resistance. For a presumed CAUTI, urine culture should be collected after replacement with a fresh catheter but prior to administering empiric antimicrobial therapy [44]. If the catheter is no longer indicated, a specimen from voided midstream urine should be acquired before antimicrobial therapy. Treatment should be streamlined according to cultures and susceptibilities [63]. If a catheter placed over 2 weeks ago is still indicated, it should be replaced at the onset of CAUTI suspicion to decrease symptoms and reduce further CA-bacteriuria.

CAUTIs should be treated with appropriate antimicrobials for 5-7 days if the patient has mild symptoms and is not severely ill [44]. For a patient with a severe infection, it is recommended to treat for 10-14 days even if the patient is no longer catheterized. A 3-day regimen may be considered in women aged 65 or less if there are no signs of upper urinary tract infection once the catheter is removed. The local antiobiogram should be used to guide empiric therapy. If fever and other clinical symptoms persist after $72 \mathrm{~h}$, urology may 
need to perform further evaluation and a longer duration of treatment may be needed [44].

\subsection{CENTRAL LINE-ASSOCIATED BLOOD STREAM INFECTION}

Intravascular devices are commonly used for various reasons including administration of IV fluids, hemodialysis, medication administration, and more [64]. These devices can cause infections referred to as central line-associated blood stream infections (CLABSIs) and are known to increase hospital length of stay (LOS) by 10-20 days and expand costs by up to additional $\$ 4,000-$ $\$ 56,000[65,66]$. In the United States, there are more than 250,000 CLABSIs every year while 80,000 occur in the ICUs [67]. CLABSIs, along with VAP, are associated with the greatest amount of deaths due to healthcare [41]. Various types of catheters are listed in Table 1.

Table 1: Types of catheters [68]

\begin{tabular}{|c|c|c|}
\hline $\begin{array}{l}\text { Peripheral venous catheter } \\
\text { peripheral arterial } \\
\text { catheter }\end{array}$ & $\begin{array}{c}\text { Short-term CVC } \\
\text { pulmonary arterial } \\
\text { catheter }\end{array}$ & $\begin{array}{l}\text { Peripherally inserted } \\
\text { central catheter (PICC) } \\
\text { Long-term CVC }\end{array}$ \\
\hline Midline catheter & $\begin{array}{c}\text { Pressure-monitoring } \\
\text { system }\end{array}$ & Totally implantable device \\
\hline
\end{tabular}

CVC: Central Venous Catheter

Symptoms of an infection may include fever, chills, unexplained hypotension, onset of altered mental status, or clinical signs around the infection site such as inflammation or purulence [69]. Positive blood cultures are also a sign of CLABSI when other sources cannot be identified. If symptoms subside after removal of the catheter within $24 \mathrm{~h}$, this is also a sign of a possible CLABSI but is not an absolute diagnosis [64,70,71]. Developing an infection in any of these devices depends on many factors: The sterility and technique upon installation, type of intravascular device used, purpose of the catheter, insertion site, how often the device is used, length of time the catheter is in place, patient characteristics, and care to avoid causing an infection [68,72]. Processes should be standardized so that maximal safety precaution will be performed such as good hand hygiene, use of chlorhexidine in alcohol when preparing the skin, proper insertion and care techniques, reporting of CLABSI rates, and assessment and re-education when needed [41]. 
For short-term catheters, $<14$ days, the roll plate (semiquantitative) technique for tip cultures should be used, whereby the catheter tip is rolled over an agar plate [73]. In pulmonary artery catheters, cultures should be collected from the introducer tip if infection is suspected [74]. These catheters are more likely to be externally colonized with skin flora.

If an infection is suspected of a long-term catheter, meaning it has been in place for 14 days or more, intraluminal pathogens are likely the cause. Culture samples should be taken from both the insertion site and hub. Semiquantitative growth of $>15$ cfus/plate with the same organism strongly suggests bacteremia from the catheter. When suspicious of an infection, remove venous access subcutaneous ports and the tip to send to the microbiology lab for qualitative cultures [75]. The most common afflicting pathogens include coagulase-negative staphylococci, S. aureus, Candida species, and enteric gram-negative bacilli. Surgically implanted catheters and peripheral central venous catheters (CVCs) may also be infected by $P$. aeruginosa $[76,77]$.

Catheter cultures should not be collected on a routine basis. Culture sampling should only be taken when the clinician suspects a CLABSI $[19,68]$. Colonization is defined as $>15 \mathrm{cfu}$ of a 5 -centimeter catheter tip using semiquantitative cultures or $>10^{2} \mathrm{cfu}$ by quantitative cultures (luminal flushing or sonication) [78]. Growth of the same microbe from one percutaneous blood culture as well as the tip of the catheter, or one blood culture from the hub and the other from a peripheral vein is definitive of a CLABSI if criteria of quantitative cultures or differential time to positivity are met $[68,78]$. Differential time to positivity is defined as microbial growth of a minimum of two hours between the samples collected from the catheter hub and samples collected from the peripheral vein $[68,78]$. Both blood samples may be taken from two separate catheter lumens if cultures are unable to be obtained from a peripheral vein. When two blood samples are cultured from catheter lumens and the quantitative cfu count is three times greater from the second sample, diagnosis of CLABSI is possible [68,78]. A CLASBI is not diagnosed if colonization of the catheter is positive but the percutaneous culture is negative [69]. Empiric antibiotics should be started after cultures are collected. Once cultures are confirmed, therapy should be optimally streamlined $[67,78]$.

Vancomycin is the drug of choice for empiric therapy in facilities where MRSA infections are common [78,79]. If the vancomycin MIC is $>2 \mathrm{mcg} \mathrm{mL}^{-1}$, other antibiotics, such as daptomycin, should be initiated. The decision to initiate gram-negative coverage should be made based on antibiogram data, severity of disease, and other risk factors. Therapy may include a fourth generation cephalosporin, carbapenem, or $\beta$-lactam $/ \beta$-lactamase combination plus or minus an aminoglycoside [68]. The day of the first negative blood culture should be counted as day one of therapy. Empiric therapy for femoral catheters in critically ill patients should include coverage of gram-negative bacilli and 
Candida species. Echinnocandins or fluconazole may be used in certain patients [80]. Fluconazole may be an option in patients without azole use in the prior 3 months and C. krusei or C. glabrata infection risk is unlikely [68]. When the catheter is removed for uncomplicated CLABSIs, therapy for 5-7days is appropriate. If the catheter is still in place, therapy along with antibiotic lock should be treated for 10-14 days [68,78].

Antibiotic lock should be used as salvage therapy in patients with CLABSI of long-term catheters along with antimicrobial therapy for 7-14 days [81]. Patients with CLABSI of a short-term catheter is likely to have an extraluminal infection, in which case antibiotic locks are ineffective [77,68]. Ideally, the antibiotic lock should be replaced every $24 \mathrm{~h}$, however, in patients with hemodialysis it is acceptable to allow the solution to dwell for no more than $48 \mathrm{~h}$ before replacing. If peripheral cultures are negative while catheter collection is positive, antibiotic lock therapy may be used alone for 10-14 days. These solutions are commonly mixed with 50-100 units of heparin or normal saline, an adequate volume to fill the catheter lumen, Vancomycin lock therapy concentrations should be $5 \mathrm{mg} \mathrm{mL}^{-1}$, at least 1000 times higher than the MIC of the pathogenic organism [79].

A transesophageal echocardiogram (TEE) should be performed in 5-7 days of bacteremia onset for patients with persistently positive blood cultures of $>72 \mathrm{~h}$ after appropriate antibiotics and catheter removal, as well as patients with a prosthetic heart valve, pacemaker, or implantable defibrillator [82]. If diagnosis of infective endocarditis or osteomyelitis is made, duration of therapy should be 6-8 weeks.

\subsection{HOSPITAL ONSET CLOSTRIDIUM DIFFICILE}

The CDC recognizes Clostridium difficile infections (CDIs) as an urgent threat to antibiotic resistance. Every year, about 500,000 people require care for CDI while mortality rates are roughly 29,000 per year. Roughly $\$ 5$ billion a year is spent on CDIs [83]. Clostridium difficile is a gram-positive spore-forming anaerobic bacillus that will colonize the gastrointestinal tract after normal flora has been altered [84]. This colonization takes place after the organism has been ingested or when exposed to environments with spores such as soil, surfaces with contaminated feces (toilets or bathtubs), dirty hands, etc. [85]. An overgrowth of $C$. difficile will cause the production and release of toxins $\mathrm{A}$ and $B$, thus resulting in inflammation of the intestinal epithelium and diarrhea [86-88]. Toxin B is more potent than toxin A and is essential for virulence [89], while toxin $A$ is responsible for severe inflammation, injury to the epithelium, and fluid secretion [90].

Exposure to spores in healthcare settings in the previous 12 weeks increases the risk of active infection. Asymptomatic colonization from healthcare 
exposure has an estimated rate of $26 \%$ while non-hospitalized patients are $2 \%$ [83]. The greatest risk factor to developing active $C$. difficile infection is recent exposure to antibiotics (usually 8 weeks or less) [91]. Older adults, 65 years and above, taking antibiotics and having frequent visits to healthcare facilities are also at an increased risk [85]. Antibiotics most commonly associated with Clostridium difficile associated diarrhea (CDAD) are clindamycin, fluoroquinolones, third and fourth generation cephalosporins, and carbapenems [92,93]. Antimicrobial stewardship plays an important role in minimizing the use of antibiotics. Other risk factors for developing CDIs include immunosuppression (chemotherapy, human immunodeficiency virus [HIV] infection, etc.) [94-96], gastrointestinal manipulation including surgery or tube feeding [97], and gastric acid-suppressing medications, such as histamine-2 blockers and proton pump inhibitors $[92,98]$.

Hospital onset or acquired C. difficile infection (HO-CDI or HA-CDI) is defined as CDI that tested positive more than three days after hospital admission $[83,99]$. CDI may be suspected if a person experiences signs and symptoms of watery diarrhea of 3 or more episodes within $24 \mathrm{~h}$ that is not attributable to other causes such as laxatives inflammatory bowel disease, enteral feeding, or cancer chemotherapy [93]. Diarrhea may also be accompanied by symptoms of fever, loss of appetite, nausea, and abdominal pain or discomfort [85]. Complications of CDI may consist of electrolyte imbalances, dehydration, hypoalbuminemia, toxic megacolon, bowel perforation, hypotension, renal failure, SIRS, sepsis, and death [100-102]. An active infection of C. difficile is confirmed by watery, loose, or unformed stool testing positive for $C$. difficile toxins [103], or radiologic findings indicating pseudomembranous colitis. When testing loose stools is not possible, for instance, in cases of suspected C. difficile due to ileus, swabbed specimens or formed stool may be acceptable. Testing on asymptomatic patients or to confirm cure of infection is not recommended. Routine testing is also not recommended due to false positive results and increased costs [104]. Methods of confirmatory testing include enzyme immunoassay (EIA), glutamate dehydrogenase (GDH), toxin testing, or nucleic acid amplification testing (NAAT).

Severity of CDI is defined by the guidelines and other literature per the chart below (Table 2) $[102,105,106]$. Others may choose to use a scoring system to define the severity of infection [107-109].

Table 2: Severity of Clostridium difficile infection

\begin{tabular}{c|c|c}
\hline Non-severe & Severe & Fulminant \\
\hline $\mathrm{WBC}<15$ cells $/ \mathrm{mL}$ & $\mathrm{WBC}>15$ cells $/ \mathrm{mL}$ & - Hypotension \\
$\mathrm{SCr}<1.5$ & $\mathrm{SCr}>1.5 \times$ baseline & - Shock \\
& & - Ileus \\
& & - Megacolon \\
\hline
\end{tabular}


To help prevent the spread of Clostridium difficile infection, protective equipment such as gloves and gowns worn by any person entering the room of a patient with an active CDI is recommended. These contact precautions along with single rooms are effective infection control methods. Good hand hygiene should also be practiced to prevent the spread of nosocomial infections. With CDI in particular, hands should be cleansed with soap and water instead of alcohol-based disinfectants. Even though clinical evidence has not shown alcohol to affect the occurrence of CDI, spore forming $C$. difficile spores are known to be resistant to alcohol $[110,111]$. Chlorine products, or other sporicidals, are useful in preventing the spread of CDI in contaminated environments [105].

Upon confirming $C$. difficile infection, discontinue any provoking therapy if possible to decrease the risk of recurrence. A newly diagnosed mild to severe CDI may be treated with vancomycin $125 \mathrm{mg}$ by mouth 4 times a day for 10 days or fidaxomicin $200 \mathrm{mg}$ twice daily for 10 days [106]. Metronidazole $500 \mathrm{mg}$ by mouth or intravenously three times daily for 10 days may be used as an alternative choice for an initial, non-severe episode if the other agents are limited. For severely complicated or fulminant CDI, vancomycin $500 \mathrm{mg}$ by mouth 4 times daily plus or minus metronidazole $500 \mathrm{mg}$ three times daily for 10 days is the treatment of choice [106]. If ileus is present, a vancomycin retention enema of $500 \mathrm{mg}$ in about $100 \mathrm{~mL}$ of normal saline every $6 \mathrm{~h}$ and metronidazole $500 \mathrm{mg}$ IV every eight hours is recommended. A subtotal colectomy preserving the rectum should be performed if surgical management is necessary. Diverting loop ileostomy with colonic lavage preceding vancomycin flushes may be used as an alternative [106]. If patients have a delayed response to any treatment, an extension to 14 days of therapy may be considered [106]. When waiting for final culture specimen results, empiric treatment may be initiated if suspicion for CDI is high [112]. If a patient experiences a recurrent CDI episode, the first recurrence can be treated with a 10-day course of vancomycin or fidaxomicin if metronidazole was used for the initial episode [106]. The use of metronidazole is not recommended in recurrent episodes due to the increased risk of neurotoxicity with cumulative levels. If standard vancomycin therapy was used to treat the primary episode, the second episode should be treated with a pulse or tapered dose of oral vancomycin, or fidaxomicin. When two or more recurrences have occurred, appropriate therapies include pulse or tapered oral vancomycin, a standard course of oral vancomycin followed by rifaximin, or fidaxomicin. Fecal microbiota transplant (FMT) may also be considered after 2 recurrences (or 3 total episodes) of CDI that were appropriately treated with antibiotics [106]. FMT should be collected from healthy donors and may be administered from a fresh or frozen fecal suspension via nasoduodenal tube or colonoscopy $[113,114]$. Other therapies that have been studied for CDI include nitazoxanide, tolevamer [115], bezlotoxumab [116], and C. diff toxoid vaccinations [117]. Bezlotoxumab $10 \mathrm{mg} \mathrm{kg}^{-1} \mathrm{IV}$ is now approved as an 
adjunctive therapy with antibiotics in patients who are at high risk of recurrent CDI. The use of probiotics are not recommended by the Society for Healthcare Epidemiology of America/Infectious Diseases Society of America (SHEA/IDSA) guidelines for primary prevention of $\mathrm{CDI}$, however, there is some evidence of a reduction in both initial and recurrent CDI [106,118-120].

\subsection{CONCLUSION}

Practices of antimicrobial stewardship are essential in helping to prevent the spread of resistance. Healthcare facilities should implement infection control programs, policies, and stewardship to help prevent the spread of resistance. Hand washing is still the cornerstone in prevention of infections and must not be underestimated or omitted by healthcare professionals. Holding work peers accountable, a well-structured plan, and close surveillance of processes help to reduce hospital acquired infections and the spread of other illnesses. Education and positive feedback from management motivates healthcare workers to utilize safe work practices and adhere to protocols. Barriers to implementation may be due to the absence of leadership, resources, and lack of sense of responsibility. Other factors may include staffing and workload. Programs to reduce HAI are highly encouraged to promote communication, teamwork, and revealing and changing unsafe practices. All healthcare workers should be active in infection prevention and control for the entire organization to promote safety for the patients as well as all employees. Guidelines and evidence-based practices should be used to guide institutional policies and should frequently be reviewed and updated when necessary. Implementing solid practices has shown to decrease mortality and morbidity caused by hospital-acquired infections. We hope that the book chapter provided clear guidance in the aforementioned conditions, will promote safe practices to prevent the cause of infections in institutional settings, bring awareness to, and prolong or stop resistance.

\section{REFERENCES}

1. A.F. Monegro, H. Regunath, Hospital Acquired Infections, StatPearls, Treasure Island (FL), 2017.

2. R. Weinstein, Infections Acquired in Health Care Facilities. in: F.A. Kasper D, S. Hauser, D. Longo, J. Jameson, J. Loscalzo (Eds.), Harrison's Principles of Internal Medicine, New York, NY, 2014.

3. R.M. Klevens, J.R. Edwards, C.L. Richards Jr., T.C. Horan, R.P. Gaynes, D.A. Pollock, D.M. Cardo, Public. Health. Rep. 122 (2007) 160-166.

4. $\quad$ S.J. Martin, R.J. Yost, J. Pharm. Pract. 24 (2011) 35-43. 
5. S.K. Fridkin, J.R. Edwards, F.C. Tenover, R.P. Gaynes, J.E. McGowan Jr, Clin. Infect. Dis. 33 (2001) 324-330.

6. R. Kohlmann, S.G. Gatermann, PLoS One 11 (2016) e0147965.

7. P. Davey, C.A. Marwick, C.L. Scott, E. Charani, K. McNeil, E. Brown, I.M. Gould, C.R. Ramsay, S. Michie, Cochrane Database Syst. Rev. 2 (2017) CD003543.

8. E.S. Dodds Ashley, K.S. Kaye, D.D. DePestel, E.D. Hermsen, Clin. Infect. Dis. 59 Suppl 3 (2014) S112-121.

9. CDC, Sepsis Data \& Reports. Atlanta, GA, 2017.

10. R.P. Dellinger, M.M. Levy, A. Rhodes, D. Annane, H. Gerlach, S.M. Opal, J.E. Sevransky, C.L. Sprung, I.S. Douglas, R. Jaeschke, T.M. Osborn, M.E. Nunnally, S.R. Townsend, K. Reinhart, R.M. Kleinpell, D.C. Angus, C.S. Deutschman, F.R. Machado, G.D. Rubenfeld, S.A. Webb, R.J. Beale, J.L. Vincent, R. Moreno, Crit. Care Med. 41 (2013) 580-637.

11. X. Fang, Z. Wang, J. Yang, H. Cai, Z. Yao, K. Li, Q. Fang, Chest (2017).

12. C.W. Seymour, V.X. Liu, T.J. Iwashyna, F.M. Brunkhorst, T.D. Rea, A. Scherag, G. Rubenfeld, J.M. Kahn, M. Shankar-Hari, M. Singer, C.S. Deutschman, G.J. Escobar, D.C. Angus, JAMA 315 (2016) 762-774.

13. M. Singer, C.S. Deutschman, C.W. Seymour, M. Shankar-Hari, D. Annane, M. Bauer, R. Bellomo, G.R. Bernard, J.D. Chiche, C.M. Coopersmith, R.S. Hotchkiss, M.M. Levy, J.C. Marshall, G.S. Martin, S.M. Opal, G.D. Rubenfeld, T. van der Poll, J.L. Vincent, D.C. Angus, JAMA 315 (2016) 801-810.

14. A. Rhodes, L.E. Evans, W. Alhazzani, M.M. Levy, M. Antonelli, R. Ferrer, A. Kumar, J.E. Sevransky, C.L. Sprung, M.E. Nunnally, B. Rochwerg, G.D. Rubenfeld, D.C. Angus, D. Annane, R.J. Beale, G.J. Bellinghan, G.R. Bernard, J.D. Chiche, C. Coopersmith, D.P. De Backer, C.J. French, S. Fujishima, H. Gerlach, J.L. Hidalgo, S.M. Hollenberg, A.E. Jones, D.R. Karnad, R.M. Kleinpell, Y. Koh, T.C. Lisboa, F.R. Machado, J.J. Marini, J.C. Marshall, J.E. Mazuski, L.A. McIntyre, A.S. McLean, S. Mehta, R.P. Moreno, J. Myburgh, P. Navalesi, O. Nishida, T.M. Osborn, A. Perner, C.M. Plunkett, M. Ranieri, C.A. Schorr, M.A. Seckel, C.W. Seymour, L. Shieh, K.A. Shukri, S.Q. Simpson, M. Singer, B.T. Thompson, S.R. Townsend, T. Van der Poll, J.L. Vincent, W.J. Wiersinga, J.L. Zimmerman, R.P. Dellinger, Intens. Care Med. 43 (2017) 304-377.

15. B. Long, A. Koyfman, K.L. Modisett, C.J. Woods, J. Emerg. Med 52 (2017) 472483.

16. P.E. Marik, Chest 145 (2014) 1407-1418.

17. M.C. Scott, H. Mallemat, Emerg. Med. Clin. North Am. 32 (2014) 811-822.

18. B. Casserly, G.S. Phillips, C. Schorr, R.P. Dellinger, S.R. Townsend, T.M. Osborn, K. Reinhart, N. Selvakumar, M.M. Levy, Crit. Care Med. 43 (2015) 567-573.

19. E.J. Baron, J.M. Miller, M.P. Weinstein, S.S. Richter, P.H. Gilligan, R.B. Thomson, Jr., P. Bourbeau, K.C. Carroll, S.C. Kehl, W.M. Dunne, B. Robinson-Dunn, J.D. Schwartzman, K.C. Chapin, J.W. Snyder, B.A. Forbes, R. Patel, J.E. Rosenblatt, B.S. Pritt, Clin. Infect. Dis. 57 (2013) e22-e121.

20. R. Ferrer, I. Martin-Loeches, G. Phillips, T.M. Osborn, S. Townsend, R.P. Dellinger, A. Artigas, C. Schorr, M.M. Levy, Crit. Care Med. 42 (2014) 17491755.

21. A. Kumar, P. Ellis, Y. Arabi, D. Roberts, B. Light, J.E. Parrillo, P. Dodek, G. Wood, A. Kumar, D. Simon, C. Peters, M. Ahsan, D. Chateau, Chest 136 (2009) 12371248. 
22. A. Kumar, D. Roberts, K.E. Wood, B. Light, J.E. Parrillo, S. Sharma, R. Suppes, D. Feinstein, S. Zanotti, L. Taiberg, D. Gurka, A. Kumar, M. Cheang, Crit. Care Med. 34 (2006) 1589-1596.

23. M. Paul, V. Shani, E. Muchtar, G. Kariv, E. Robenshtok, L. Leibovici, Antimicrob. Agents Chemother. 54 (2010) 4851-4863.

24. E. de Jong, J.A. van Oers, A. Beishuizen, P. Vos, W.J. Vermeijden, L.E. Haas, B.G. Loef, T. Dormans, G.C. van Melsen, Y.C. Kluiters, H. Kemperman, M.J. van den Elsen, J.A. Schouten, J.O. Streefkerk, H.G. Krabbe, H. Kieft, G.H. Kluge, V.C. van Dam, J. van Pelt, L. Bormans, M.B. Otten, A.C. Reidinga, H. Endeman, J.W. Twisk, E.M.W. van de Garde, A. de Smet, J. Kesecioglu, A.R. Girbes, M.W. Nijsten, D.W. de Lange, Lancet Infect. Dis. 16 (2016) 819-827.

25. J. Garnacho-Montero, A. Gutierrez-Pizarraya, A. Escoresca-Ortega, Y. CorciaPalomo, E. Fernandez-Delgado, I. Herrera-Melero, C. Ortiz-Leyba, J.A. MarquezVacaro, Intens. Care Med. 40 (2014) 32-40.

26. A. Prkno, C. Wacker, F.M. Brunkhorst, P. Schlattmann, Crit. Care 17 (2013) R291.

27. M. Paul, Y. Dickstein, A. Raz-Pasteur, Clin. Microbiol. Infect. 22 (2016) 960-967.

28. A.C. Kalil, M.L. Metersky, M. Klompas, J. Muscedere, D.A. Sweeney, L.B. Palmer, L.M. Napolitano, N.P. O'Grady, J.G. Bartlett, J. Carratala, A.A. El Solh, S. Ewig, P.D. Fey, T.M. File, Jr., M.I. Restrepo, J.A. Roberts, G.W. Waterer, P. Cruse, S.L. Knight, J.L. Brozek, Clin. Infect. Dis. 63 (2016) e61-e111.

29. P. Depuydt, D. Benoit, D. Vogelaers, J. Decruyenaere, D. Vandijck, G. Claeys, G. Verschraegen, S. Blot, Intens. Care Med. 34 (2008) 675-682.

30. E. Giantsou, N. Liratzopoulos, E. Efraimidou, M. Panopoulou, E. Alepopoulou, S. Kartali-Ktenidou, G.I. Minopoulos, S. Zakynthinos, K.I. Manolas, Intens. Care Med. 31 (2005) 1488-1494.

31. J.L. Trouillet, J. Chastre, A. Vuagnat, M.L. Joly-Guillou, D. Combaux, M.C. Dombret, C. Gibert. Am J Respir Crit. Care Med. 157 (1998) 531-539.

32. P. Gastmeier, D. Sohr, C. Geffers, H. Ruden, R.P. Vonberg, T. Welte. Antimicrob. Agents Chemother. 53 (2009) 2714-2718.

33. E.H. Ibrahim, S. Ward, G. Sherman, M.H. Kollef, Chest 117 (2000) 1434-1442.

34. I. Martin-Loeches, M. Deja, D. Koulenti, G. Dimopoulos, B. Marsh, A. Torres, M.S. Niederman, J. Rello, E.-V.S. Investigators, Intens. Care Med. 39 (2013) 672-681.

35. M.Z. David, M. Dryden, T. Gottlieb, P. Tattevin, I.M. Gould, Int. J. Antimicrob. Agents 50 (2017) 303-307.

36. S.M. Purrello, J. Garau, E. Giamarellos, T. Mazzei, F. Pea, A. Soriano, S. Stefani, J. Glob. Antimicrob. Resist. 7 (2016) 178-186.

37. T. Welte, M.W. Pletz, Int. J. Antimicrob. Agents 36 (2010) 391-400.

38. R.A. Khan, M.M. Bakry, F. Islahudin, Indian J. Pharm. Sci. 77 (2015) 299-305.

39. R.G.W. Lionel A Mandell, Dennis Kasper, et al., Pneumonia, Harrison's Principles of Internal Medicine 19th Ed., McGraw-Hill, New York, 2014.

40. CDC. Antibiotic Threats in the United States, 2013. 2013, pp. 51-52.

41. J.A. Al-Tawfiq, P.A. Tambyah, J. Infect. Public Health 7 (2014) 339-344.

42. D.S. Yokoe, D.J. Anderson, S.M. Berenholtz, D.P. Calfee, E.R. Dubberke, K.D. Ellingson, D.N. Gerding, J.P. Haas, K.S. Kaye, M. Klompas, E. Lo, J. Marschall, L.A. Mermel, L.E. Nicolle, C.D. Salgado, K. Bryant, D. Classen, K. Crist, V.M. Deloney, N.O. Fishman, N. Foster, D.A. Goldmann, E. Humphreys, J.A. Jernigan, J. Padberg, T.M. Perl, K. Podgorny, E.J. Septimus, M. VanAmringe, T. Weaver, R.A. 
Weinstein, R. Wise, L.L. Maragakis, Infect. Control Hosp. Epidemiol. 35 (2014) 967-977.

43. K. Gupta, Trautner BW Urinary Tract Infections, Pyelonephritis, and Prostatitis. in: e.a. Dennis Kasper (Ed.), Harrison's Principles of Internal Medicine, McGraw-Hill, New York, NY, 2014.

44. T.M. Hooton, S.F. Bradley, D.D. Cardenas, R. Colgan, S.E. Geerlings, J.C. Rice, S. Saint, A.J. Schaeffer, P.A. Tambayh, P. Tenke, L.E. Nicolle, Clin. Infect. Dis. 50 (2010) 625-663.

45. L.E. Nicolle, Infect. Dis. Clin. North Am. 26 (2012) 13-27.

46. CDC. Catheter-associated Urinary Tract Infections (CAUTI). 2017.

47. A.I. Hartstein, S.B. Garber, T.T. Ward, S.R. Jones, V.H. Morthland, Infect. Control 2 (1981) 380-386.

48. S. National Nosocomial Infections Surveillance, Am. J. Infect. Control 32 (2004) 470-485.

49. B.E. Kreger, D.E. Craven, P.C. Carling, W.R. McCabe, Am. J. Med. 68 (1980) 332343.

50. C. Chenoweth, S. Saint, Crit. Care Clin. 29 (2013) 19-32.

51. J.W. Warren, Infect. Dis. Clin. North Am. 11 (1997) 609-622.

52. R.A. Garibaldi, J.P. Burke, M.L. Dickman, C.B. Smith, N. Engl. J. Med. 291 (1974) 215-219.

53. D.G. Maki, P.A. Tambyah, Emerg. Infect. Dis. 7 (2001) 342-347.

54. S. Saint, C.E. Chenoweth, Infect. Dis. Clin. North Am. 17 (2003) 411-432.

55. S.M. Jacobsen, D.J. Stickler, H.L. Mobley, M.E. Shirtliff, Clin. Microbiol. Rev. 21 (2008) 26-59.

56. P.A. Tambyah, D.G. Maki, Arch. Intern. Med. 160 (2000) 678-682.

57. L.E. Nicolle, Drugs Aging 22 (2005) 627-639.

58. $\quad$ K. Schumm, T.B. Lam, Neurourol. Urodyn. 27 (2008) 738-746.

59. C.J. Crnich, P.J. Drinka, Infect. Control Hosp. Epidemiol. 28 (2007) 102-103.

60. A. Srinivasan, T. Karchmer, A. Richards, X. Song, T.M. Perl, Infect. Control Hosp. Epidemiol. 27 (2006) 38-43.

61. J.H. Tenney, J.W. Warren, J. Infect. Dis. 157 (1988) 199-202.

62. R. Raz, D. Schiller, L.E. Nicolle, J. Urol. 164 (2000) 1254-1258.

63. L.E. Nicolle, Drugs Aging 18 (2001) 243-254.

64. M.L. Maki DG, Lippin- cott-Raven (1998) 689-724.

65. S.I. Blot, P. Depuydt, L. Annemans, D. Benoit, E. Hoste, J.J. De Waele, J. Decruyenaere, D. Vogelaers, F. Colardyn, K.H. Vandewoude, Clin. Infect. Dis. 41 (2005) 1591-1598.

66. B. Renaud, C. Brun-Buisson, I.C.-B.S. Group, Am. J. Respir. Crit. Care Med. 163 (2001) 1584-1590.

67. H. Shah, W. Bosch, K.M. Thompson, W.C. Hellinger, Neurohospitalist 3 (2013) 144-151.

68. L.A. Mermel, M. Allon, E. Bouza, D.E. Craven, P. Flynn, N.P. O'Grady, Raad, II, B.J. Rijnders, R.J. Sherertz, D.K. Warren, Clin. Infect. Dis. 49 (2009) 1-45.

69. R. Gahlot, C. Nigam, V. Kumar, G. Yadav, S. Anupurba, Int. J. Crit. Illn. Inj. Sci. 4 (2014) 162-167.

70. C.G. Mayhall, Curr. Clin. Top. Infect. Dis. 12 (1992) 83-110.

71. N. Safdar, D.G. Maki, Crit. Care Med. 30 (2002) 2632-2635.

72. D.G. Maki, D.M. Kluger, C.J. Crnich, Mayo. Clin. Proc. 81 (2006) 1159-1171. 
73. E. Bouza, N. Alvarado, L. Alcala, M. Sanchez-Conde, M.J. Perez, P. Munoz, P. Martin-Rabadan, M. Rodriguez-Creixems, Clin. Infect. Dis. 40 (2005) 10961100.

74. L.A. Mermel, R.D. McCormick, S.R. Springman, D.G. Maki. Am. J. Med. 91 (1991) 197S-205S.

75. E. Bouza, N. Alvarado, L. Alcala, M.J. Perez, C. Rincon, P. Munoz, Clin Infect Dis. 44 (2007) 820-826.

76. $\quad$ D.G. Maki, S.M. Stolz, S. Wheeler, L.A. Mermel, Ann Intern Med 127 (1997) 257266.

77. I. Raad, W. Costerton, U. Sabharwal, M. Sacilowski, E. Anaissie, G.P. Bodey, J. Infect. Dis. 168 (1993) 400-407.

78. Z. Han, S.Y. Liang, J. Marschall. Infect. Drug Resist. 3 (2010) 147-163.

79. I.D. Maya, D. Carlton, E. Estrada, M. Allon, Am. J. Kidney Dis. 50 (2007) 289295.

80. A.C. Reboli, C. Rotstein, P.G. Pappas, S.W. Chapman, D.H. Kett, D. Kumar, R. Betts, M. Wible, B.P. Goldstein, J. Schranz, D.S. Krause, T.J. Walsh, N. Engl. J. Med. 356 (2007) 2472-2482.

81. N. Fernandez-Hidalgo, B. Almirante, R. Calleja, I. Ruiz, A.M. Planes, D. Rodriguez, C. Pigrau, A. Pahissa, J. Antimicrob. Chemother. 57 (2006) 11721180.

82. C. Pigrau, D. Rodriguez, A.M. Planes, B. Almirante, N. Larrosa, E. Ribera, J. Gavalda, A. Pahissa, Eur. J. Clin. Microbiol. Infect. Dis. 22 (2003) 713-719.

83. F.C. Lessa, Y. Mu, W.M. Bamberg, Z.G. Beldavs, G.K. Dumyati, J.R. Dunn, M.M. Farley, S.M. Holzbauer, J.I. Meek, E.C. Phipps, L.E. Wilson, L.G. Winston, J.A. Cohen, B.M. Limbago, S.K. Fridkin, D.N. Gerding, L.C. McDonald,. N. Engl. J. Med. 372 (2015) 825-834.

84. J.G. Bartlett, Clin. Infect. Dis. 46 Suppl 1 (2008) S4-11.

85. CDC. Clostridium difficile Infection. 2016.

86. D.A. Caroff, D.S. Yokoe, M. Klompas, Clin. Infect. Dis. (2017).

87. D.A. Leffler, J.T. Lamont, N. Engl. J. Med. 372 (2015) 1539-1548.

88. K. Traugott. Chapter 33. Clostridium Difficile Infections. in: M.M. Attridge RL, Moote R, Ryan L. (Ed.), McGraw-Hill, New York, NY, 2013.

89. D. Lyras, J.R. O'Connor, P.M. Howarth, S.P. Sambol, G.P. Carter, T. Phumoonna, R. Poon, V. Adams, G. Vedantam, S. Johnson, D.N. Gerding, J.I. Rood, Nature 458 (2009) 1176-1179.

90. M. Riegler, R. Sedivy, C. Pothoulakis, et al., J. Clin. Invest. 95 (1995) 2004-2011.

91. D.N. Gerding, M.M. Olson, L.R. Peterson, D.G. Teasley, R.L. Gebhard, M.L. Schwartz, J.T. Lee, Jr, Arch. Intern. Med. 146 (1986) 95-100.

92. V. Stevens, G. Dumyati, L.S. Fine, S.G. Fisher, E. van Wijngaarden, Clin. Infect. Dis. 53 (2011) 42-48.

93. M.P. Hensgens, A. Goorhuis, O.M. Dekkers, E.J. Kuijper, J. Antimicrob. Chemother. 67 (2012) 742-748.

94. S. Bilgrami, J.M. Feingold, D. Dorsky, R.L. Edwards, R.D. Bona, A.M. Khan, F. Rodriguez-Pinero, J. Clive, P.J. Tutschka, Bone Marrow Transplant. 23 (1999) 1039-1042.

95. M. Gorschluter, A. Glasmacher, C. Hahn, F. Schakowski, C. Ziske, E. Molitor, G. Marklein, T. Sauerbruch, I.G. Schmidt-Wolf, Clin. Infect. Dis. 33 (2001) 786791. 
96. T.H. Sanchez, J.T. Brooks, P.S. Sullivan, M. Juhasz, E. Mintz, M.S. Dworkin, J.L. Jones, Clin. Infect. Dis. 41 (2005) 1621-1627.

97. A. Thibault, M.A. Miller, C. Gaese, Infect. Control Hosp. Epidemiol. 12 (1991) 345-348.

98. C. Bavishi, H.L. Dupont, Aliment. Pharmacol. Ther. 34 (2011) 1269-1281.

99. D.M. Faleck, H. Salmasian, E.Y. Furuya, E.L. Larson, J.A. Abrams, D.E. Freedberg, Am. J. Gastroenterol. 111 (2016) 1641-1648.

100. L. Kyne, C. Merry, B. O'Connell, A. Kelly, C. Keane, D. O'Neill, Age Ageing 28 (1999) 107-113.

101. V.G. Loo, L. Poirier, M.A. Miller, M. Oughton, M.D. Libman, S. Michaud, A.M. Bourgault, T. Nguyen, C. Frenette, M. Kelly, A. Vibien, P. Brassard, S. Fenn, K. Dewar, T.J. Hudson, R. Horn, P. Rene, Y. Monczak, A. Dascal, N. Engl. J. Med. 353 (2005) 2442-2449.

102. S.H. Cohen, D.N. Gerding, S. Johnson, C.P. Kelly, V.G. Loo, L.C. McDonald, J. Pepin, M.H. Wilcox, Infect. Control Hosp. Epidemiol. 31 (2010) 431-455.

103. D.N. Gerding, Am. J. Med. 100 (1996) 485-486.

104. E. Aichinger, C.D. Schleck, W.S. Harmsen, L.M. Nyre, R. Patel, J. Clin. Microbiol. 46 (2008) 3795-3797.

105. D.L. McCollum, J.M. Rodriguez, Clin. Gastroenterol. Hepatol. 10 (2012) 581592.

106. L.C. McDonald, D.N. Gerding, S. Johnson, J.S. Bakken, K.C. Carroll, S.E. Coffin, E.R. Dubberke, K.W. Garey, C.V. Gould, C. Kelly, V. Loo, J. Shaklee Sammons, T.J. Sandora, M.H. Wilcox, Clin. Infect. Dis. (2018).

107. N. Bagdasarian, K. Rao, P.N. Malani. JAMA 313 (2015) 398-408.

108. M.A. Miller, T. Louie, K. Mullane, K. Weiss, A. Lentnek, Y. Golan, Y. Kean, P. Sears, BMC Infect. Dis. 13 (2013) 148.

109. F.A. Zar, S.R. Bakkanagari, K.M. Moorthi, M.B. Davis, Clin. Infect. Dis. 45 (2007) 302-307.

110. M.T. Oughton, V.G. Loo, N. Dendukuri, S. Fenn, M.D. Libman, Infect. Control Hosp. Epidemiol. 30 (2009) 939-944.

111. M. Wullt, I. Odenholt, M. Walder, Infect. Control Hosp. Epidemiol. 24 (2003) 765-768.

112. C.M. Surawicz, L.J. Brandt, D.G. Binion, A.N. Ananthakrishnan, S.R. Curry, P.H. Gilligan, L.V. McFarland, M. Mellow, B.S. Zuckerbraun, Am. J. Gastroenterol. 108 (2013) 478-498; quiz 499.

113. E. van Nood, A. Vrieze, M. Nieuwdorp, S. Fuentes, E.G. Zoetendal, W.M. de Vos, C.E. Visser, E.J. Kuijper, J.F. Bartelsman, J.G. Tijssen, P. Speelman, M.G. Dijkgraaf, J.J. Keller, N. Engl. J. Med. 368 (2013) 407-415.

114. I. Youngster, J. Sauk, C. Pindar, R.G. Wilson, J.L. Kaplan, M.B. Smith, E.J. Alm, D. Gevers, G.H. Russell, E.L. Hohmann, Clin. Infect. Dis. 58 (2014) 1515-1522.

115. S. Johnson, T.J. Louie, D.N. Gerding, O.A. Cornely, S. Chasan-Taber, D. Fitts, S.P. Gelone, C. Broom, D.M. Davidson, Clin. Infect. Dis. 59 (2014) 345-354.

116. M.H. Wilcox, D.N. Gerding, I.R. Poxton, C. Kelly, R. Nathan, T. Birch, O.A. Cornely, G. Rahav, E. Bouza, C. Lee, G. Jenkin, W. Jensen, Y.S. Kim, J. Yoshida, L. Gabryelski, A. Pedley, K. Eves, R. Tipping, D. Guris, N. Kartsonis, M.B. Dorr, I. Modify, M.I. Investigators, N. Engl. J. Med. 376 (2017) 305-317.

117. R. Leuzzi, R. Adamo, M. Scarselli, Hum. Vaccin Immunother. 10 (2014) 14661477.

118. L.V. McFarland, Anaerobe 15 (2009) 274-280. 
119. J.Z. Goldenberg, S.S. Ma, J.D. Saxton, M.R. Martzen, P.O. Vandvik, K. Thorlund, G.H. Guyatt, B.C. Johnston, Cochrane Database Syst. Rev. (2013) CD006095.

120. B.C. Johnston, S.S. Ma, J.Z. Goldenberg, K. Thorlund, P.O. Vandvik, M. Loeb, G.H. Guyatt, Ann. Intern. Med. 157 (2012) 878-888.

(C)2018 by the authors; licensee IAPC, Zagreb, Croatia. This chapter is an open-access publication distributed under the terms and conditions of the Creative Commons Attribution license (http://creativecommons.org/licenses/by/3.0/) (cc) Br 
Chapter 5

114 